\title{
Circuitos de fluxos sócioespaciais da indústria têxtil e impactos ambientais em Jardim de Piranhas-RN*
}

\author{
Rosalvo Nobre Carneiro \\ Josiel de Alencar Guedes**
}

\section{Resumo}

Circuitos de fluxos sociais e circuitos espaciais da produção juntos conformam o que Carneiro (2006, 2008 e 2011) chama de circuitos de fluxos sócioespaciais. Foi realizada uma pesquisa de campo na cidade de Jardim de Piranhas no ano de 2008, ocasião em que foram entrevistados empresários de 06 unidades de produção familiar, doméstica e médias e grandes empresas locais, bem como os operários das fábricas. Essas indústrias concentram suas produções na confecção têxtil de panos de prato e produtos substitutos como redes de dormir. Por estarem localizadas, principalmente nas proximidades do rio Piranhas-açú, geram impactos ambientais, resultados das atividades produtivas desta indústria, que se diferenciam conforme as fábricas pertençam aos circuitos de fluxos sócioespaciais inferiores ou aos circuitos de fluxos socioespaciais superiores secundários.

Palavras-chave: Indústria têxtil; Circuitos de fluxos sócioespaciais; Impactos ambientais.

* Este trabalho foi financiado pelo Convênio 11/2008, BNB/FASE/UERN e concluído em 2011, a partir dos resultados da pesquisa "Produção do espaço regional e indústria têxtil de Jardim de Piranhas-RN: uma análise comparativa com Jaguaruana-CE”.

** Professor do Programa de Pós-graduação em Ciências Sociais e Humanas - PPGCISH/UERN e Curso de Geografia, UERN, CAMEAM (rosalvocarneiro@uern.br).

Professor Curso de Geografia, UERN, CAMEAM, (josielguedes@uern.br)

Geosul, Florianópolis, v. 28, n. 55, p 103-122, jan./jun. 2013 
CARNEIRO, R.N. \& GUEDES, J.A. Circuitos de fluxos sócioespaciais da...

Sociospatial flows circuits in the textile industry and environment impacts in Jardim de Piranhas-RN

\begin{abstract}
Circuits of flows and social space circuits of production together constitute what Carneiro (2006, 2008 and 2011) calls circuits of flows sociospatial. A study was carried out in the field in the city of the Jardim de Piranhas in the year 2008, on the occasion of which were interviewed entrepreneurs of 06 production units family, domestic and medium and large local companies, as well as the laborers of the factories. These industries are concentrated their productions in the textile confection of dish cloths and substitute products such as hammock. These industries located in the vicinity of the Piranhas-açu river, generate environmental impacts, results of productive activities, which differ according to the factories activities belonging to the circuits of flows sociospatial below or to the circuits of flows sociospatial upper secondary.
\end{abstract}

Key words: Textile industry; Flows sociospatial circuits; Environment impacts.

\title{
Introdução
}

O tamanho dos impactos ambientais em determinado lugar pode ser analisado a partir do tamanho das empresas ou atividades produtivas e da sua escala de sua produção, distribuição, circulação e consumo. No primeiro caso fala-se em circuitos de fluxos sociais e no segundo em circuitos espaciais da produção.

Circuitos de fluxos sociais e circuitos espaciais da produção juntos conformam o que aqui se chama circuitos de fluxos sócioespaciais. Para Carneiro (2011), amparado na Teoria dos Dois Circuitos da Economia Urbana, os circuitos de fluxos sócioespaciais não se limitariam aos aspectos econômicos ou do mundo sistêmico bem como ao espaço urbano, mas incluiriam 
CARNEIRO, R.N. \& GUEDES, J.A. Circuitos de fluxos sócioespaciais da...

também elementos do mundo vivido se realizando no espaço em sua totalidade, incluindo campo e cidade.

A indústria têxtil de panos de prato e produtos substitutos ${ }^{1}$ de Jardim de Piranhas, a exemplo de redes de dormir, tapetes, conjuntos de capas para utensílios do lar, mantas dentre outros, representa o maior polo destes tipos de produtos no estado do Rio Grande do Norte, a qual gera emprego, trabalho e renda para a maioria de sua população.

Cortada pelo rio Piranhas, a cidade de Jardim de Piranhas concentra a totalidade das fábricas desta indústria, estando uma parte significativa localizada nas proximidades deste curso d'água. Resulta daí uma preocupação em se compreender os impactos ambientais gerados pelas atividades produtivas desta indústria conforme suas dimensões.

Assim, de um lado, têm-se fábricas que por suas características familiares e de pequenas dimensões em geral unidades de produção doméstica se situam no circuito de fluxos inferior informal e formal. De outro lado, têm-se fábricas que por seu porte médio ou grande se enquadram no circuito de fluxos superior secundário ${ }^{2}$.

No ano de 2008, no âmbito da pesquisa convênio 11/2008 BNB/FASE/UERN "Produção do espaço regional e indústria têxtil de Jardim de Piranhas-RN: uma análise comparativa com Jaguaruana-CE" foi realizada uma pesquisa na área em estudo com empresários proprietários de unidades de produção familiar e doméstica bem como em unidades de porte médio e grande.

${ }^{1}$ Carneiro (2011) caracteriza a indústria têxtil de Jardim de Piranhas-RN, São Bento-PB, Jaguaruana-CE e Tacaratu-PE, sendo formada por um produto central e outros secundários, chamados de substitutos, a partir da leitura de Michael Porter.

${ }^{2}$ Carneiro (2006 e 2011) admite ainda a existência nas economias dos países em desenvolvimento dos circuitos de fluxos sócioespaciais superiores hegemônicos e dos superiores não-hegemônicos. Estes dois não são encontrados na indústria têxtil de Jardim de Piranhas. 
CARNEIRO, R.N. \& GUEDES, J.A. Circuitos de fluxos sócioespaciais da...

Dados colhidos no interior das fábricas sobre o processo de produção, incluindo volume produzido e o adquirido de matérias primas, como fios de algodão e produtos químicos, dentre outras informações foi possível identificar processos locais de degradação ambiental, especialmente impactantes do rio Piranhas.

Além de entrevistas com trabalhadores das fábricas acerca de suas condições de trabalho fez-se um breve reconhecimento das condições sanitárias na zona urbana, com destaque para a rede de esgotos, cujos dejetos industriais seguem sem nenhum processo de tratamento, para desaguar no rio Piranhas.

As fábricas pertencentes aos circuitos de fluxos sócioespaciais inferiores, informais ou formais, assim como as pertencentes ao superior secundário são geradoras de resíduos sólidos e líquidos, degradantes do ambiente, em maior ou menor grau. Como assinala Ramos et. al. (2007, p. 20) "Os impactos ambientais do funcionamento do pólo têxtil de Jardim de Piranhas são, talvez, a maior ameaça à continuidade do embrião de APL".

$\mathrm{O}$ artigo está dividido em duas seções. Na primeira é descrito os circuitos de fluxos sócioespaciais existentes na indústria têxtil de Jardim de Piranhas e na segunda são apresentados os impactos ambientais oriundos dos mesmos bem como de outros impactos associados e ele, no principal manancial, responsável pelo abastecimento do município, o rio Piranhas.

\section{Circuitos de fluxos sócioespaciais da indústria têxtil em Jardim de Piranhas}

Para Carneiro (2009) as relações entre economia e desenvolvimento regional devem ser vistas através da análise dos circuitos de fluxos sócioespaciais, que expressam as interações territoriais entre mundo da vida e mundo do sistema econômico e político. Esta relação se estende para a análise dos impactos ambientais, pois estes circuitos são formados por empresas de variados portes e capacidades de geração de resíduos e degradação ambiental. 
CARNEIRO, R.N. \& GUEDES, J.A. Circuitos de fluxos sócioespaciais da...

As atividades fabris formadas por empresas familiares, domésticas e de pequeno porte presentes em Jardim de PiranhasRN e ligadas à indústria têxtil de fabricação de panos de pratos e produtos substitutos conformam os circuitos de fluxos inferiores informais e formais (Figura 01-a), ao passo que as médias e grandes empresas são integrantes do circuito de fluxos superior secundário (Figura 01-b).

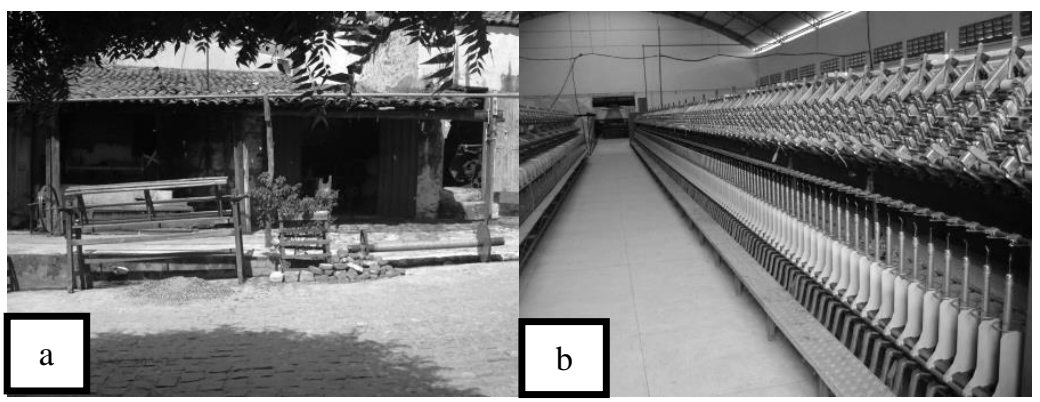

Figura 01: Exemplo de pequena (a) e grande tecelagem (b) no município de Jardim de Piranhas-RN. Foto: Os Autores.

Cada um destes circuitos de fluxos ou suas empresas mantém interações variadas com o mundo vivido, cujo processo de colonização deste pelo mundo sistêmico de mercado, simbolizado no dinheiro e no poder político-organizacional (HABERMAS, 2003) implica na submissão da produção e reprodução territorial às normas instrumentais do mercado e legais do Estado.

Estruturado a partir da razão e da ação comunicativa cujo fundamento está na busca de entendimento mútuo livre de coação entre, no mínimo, dois atores sociais o mundo vivido se encontra em processo de colonização pelo mundo sistêmico de mercado. Nesta ótica vislumbram-se em Jardim de Piranhas processos de colonização dos circuitos de fluxos sócioespaciais de fabricação de panos de prato instrumentalmente organizados, a exemplo da formalização das empresas. 
CARNEIRO, R.N. \& GUEDES, J.A. Circuitos de fluxos sócioespaciais da...

A indústria têxtil de Jardim de Piranhas teve início a partir das últimas duas décadas do século passado. Porem tomando por base as empresas analisadas percebe-se que duas surgiram entre 1981-1985, duas no período entre 1996-2000 e duas entre 2001 -2010. O maior surgimento recente das empresas deve-se coincide com a emergência do "período técnico-científico-informacional maquinofatureiro" para usar a expressão de Carneiro (2006) - deste município segundo estudo realizado por Santos e Carneiro (2009).

Assim, o "período técnico-científico-informacional maquinofatureiro" é o momento cuja indústria têxtil local se industrializa e ultrapassa a produção manufatureira. Estas fábricas surgiram a partir de herança familiar (02), resultado de investimento com capital próprio (02), enquanto 01 fabrica surgiu a partir de empréstimos de terceiros, ao passo que outro não soube explicar, o que revela o baixo grau de financeirização da economia local, cuja expressão visível é a ausência de bancos no município.

Quanto ao acesso a matérias-primas, fio de algodão e tintas, as mesmas são adquiridas tanto na própria cidade de Jardim de Piranhas (Figura 02), quanto na cidade vizinha paraibana de São Bento, sendo esta considerada o maior polo têxtil de redes de dormir do Brasil, em cidades do Estado do Ceará e dos Estados de Minas Gerais e Maranhão. Há certa fragilidade e concentração quanto ao fornecimento deste serviço no território local. Além de fio há também o uso de tecidos gabardine para confecção de diversos produtos, como redes e tapetes, e advém de vários lugares.

Percebe-se que o fio de algodão é a principal matéria-prima, com um consumo médio anual de 52,80 toneladas, seguido por tintas, com 25,88 toneladas. O cloro fica em último lugar, uma vez que se notou o declínio do seu uso pelas fábricas. As tintas também têm diminuído o seu consumo em função do fio de algodão tingido que é vendido pelos depósitos locais.

As fábricas pesquisadas informaram uma produção anual variada e diversificada, girando em torno de 120.000 unidades de tapetes, 60.000 de toalhas e 24.000 de mantas e 14.4000 de panos 
CARNEIRO, R.N. \& GUEDES, J.A. Circuitos de fluxos sócioespaciais da...

de prato. As produções de jogos de cozinha, jogos de mesa, redes de dormir e tecido, apresentam produções bem inferiores.

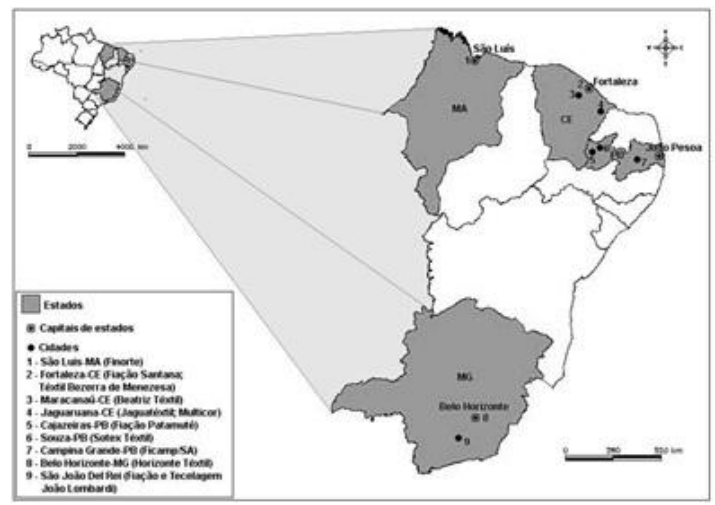

Figura 02: Espaços fornecedores de matérias-primas, incluindo fios e tecidos, para a indústria têxtil local. Fonte: Santos; Carneiro (2009).

Os produtos fabricados são distribuídos, na maioria dos casos por transportadoras locais, às vezes pessoalmente, usando alternativos, ou distribuídos para o mercado consumidor local. Isto revela a necessidade de incentivar a abertura de empresas especializadas no frete de mercadorias para todo o território nacional, como tem feito São Bento.

$\mathrm{O}$ mercado consumidor, no entanto, é formado por todo o Brasil (Figura 03), mas Jardim de Piranhas (RN) e São Bento (PB) aparecem como mercado consumidor principal, neste último caso como mercado consumidor de pequenas fábricas. Apesar de certa concentração das vendas no Nordeste brasileiro, as mercadorias locais chegam por outros meios até países sul-americanos.

Além de comercializar suas mercadorias, Jardim de Piranhas negocia máquinas, peças e acessório para diversos lugares do Nordeste (Figura 04), como máquinas adquiridas de segunda-mão utilizadas localmente e vendidas localmente. 
CARNEIRO, R.N. \& GUEDES, J.A. Circuitos de fluxos sócioespaciais da...

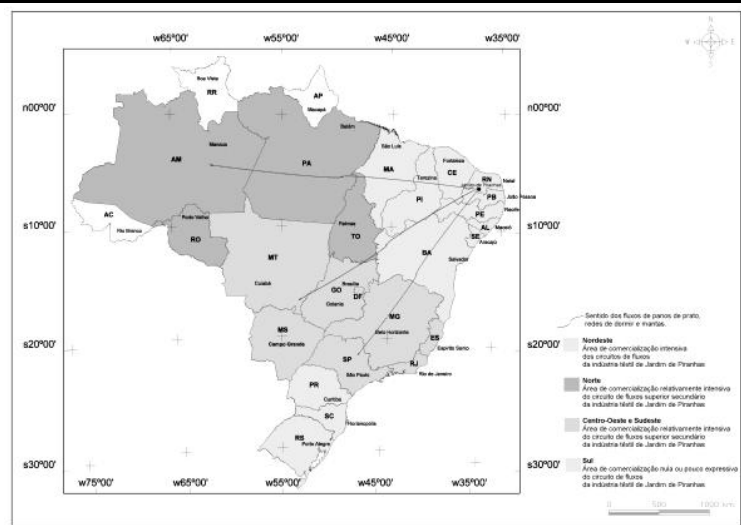

Figura 03: Circuito espacial da produção nacional de Jardim de Piranhas-RN: mercado consumidor de produtos têxteis locais. Elaboração cartográfica: Rosalvo Nobre Carneiro (2011).

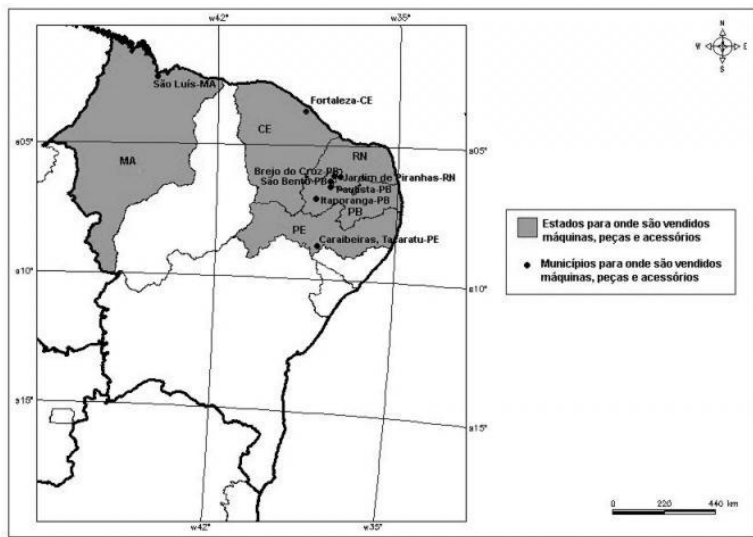

Figura 04: Jardim de Piranhas-RN: mercado consumidor de máquinas, peças e acessórios da indústria têxtil local. Fonte: Santos; Carneiro (2009).

Apesar do declínio que a indústria têxtil de redes de dormir sofreu nas últimas três décadas não apenas na região Nordeste, a exemplo de Boqueirão-PB (SILVA, 1997) e Jaguaruana-CE 
CARNEIRO, R.N. \& GUEDES, J.A. Circuitos de fluxos sócioespaciais da...

(PESSOA, 2003), motivadas nestes casos em grande parte pelo maior crescimento e concorrência da indústria têxtil de São BentoPB, em Jardim de Piranhas esta atividade se fortaleceu, apesar de sua informalidade, do deficiente apoio institucional e acesso a mercados que a mesma enfrenta (CARNEIRO, 2006).

Este fortalecimento, no caso de Jardim de Piranhas, é resultado da conjugação de eventos externos, particularmente da difusão industrial de São Bento a partir da década de 1970 e da proximidade a este centro industrial paraibano bem com de condições internas, especialmente em função da adoção célere das técnicas artesanais de fabricação e posteriormente das técnicas mecânicas, incluindo teares, espuladeiras, urdideiras movidas à energia elétrica e de comercialização de seus produtos têxteis com implicações em seu mundo vivido.

A indústria têxtil em Jardim de Piranhas é essencialmente urbana, não sendo encontrada na zona rural. Este fato gera migrações cidade-campo, já que a zona rural não é capaz de sustentar as famílias. Por outro lado, as fábricas e especialmente os serviços à produção e pessoais que geram ao seu redor permite o acesso ao trabalho, ainda que mal pago. Por outro lado, o "inchaço urbano" desta cidade tem rebatimentos ambientais pela concentração demográfica.

Além do êxodo rural, há certa migração intra-estadual para Jardim de Piranhas, motivada pela presença de sua indústria têxtil, conformando um circuito espacial da produção regional (Figura 05), isto é, uma área de influência desta cidade, gestada a partir de suas atividades fabris.

Ao lado deste sistema de objetos instala-se um sistema de ações correspondente, exigindo para cada instrumento de trabalho um ator específico a exercer sua ação nas mais diversas condições. As relações sociais de produção são mais ou menos corretas a vida ou mais ou menos adequadas ao mercado conforme as empresas e o espaço em que se localiza. Assim é o caso do trabalho que se realiza com a observância legal ou não das horas de trabalho semanais, pois o salário aí em geral é por produção, com o operário 
CARNEIRO, R.N. \& GUEDES, J.A. Circuitos de fluxos sócioespaciais da...

iniciando seu trabalho muito cedo e muito tarde o encerrando. $\mathrm{O}$ prolongamento da jorna da de trabalho resulta em maior produtividade e maior uso de matérias primas, por conseguinte maior produção de resíduos sólidos e líquidos.

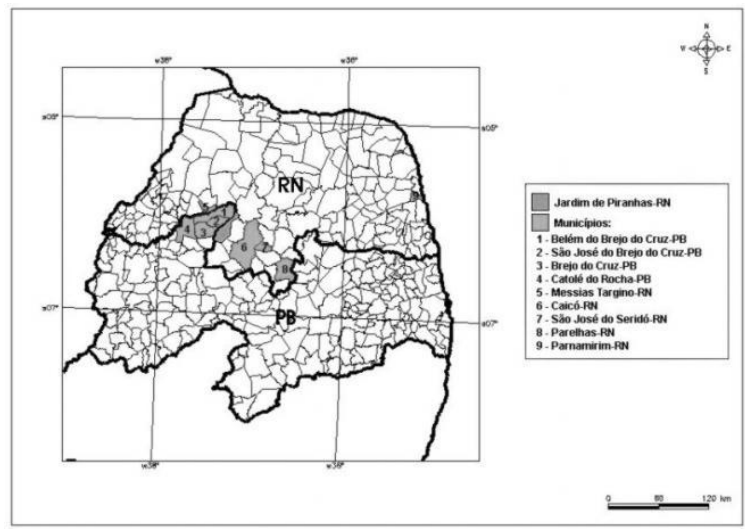

Figura 05: Jardim de Piranhas-RN: espaço fornecedor de mão de obra para a indústria têxtil local. Fonte: Santos; Carneiro (2009).

A histórica informalidade da economia expressa na enorme quantidade de trabalhadores fabris sem carteira assinada, e a prevalência de ações intersubjetivamente realizadas entre os atores sociais locais revelam que a linguagem foi um meio necessário de coordenação dos planos de ação dos atores sociais de Jardim de Piranhas. Mais agravante é a situação dos prestadores de serviços às empresas, composto pelas feiteiras (Figura 06-a), cujo trabalho se realiza em suas residências, baseados em preços aviltantes por peças acabadas e sem qualquer direito legal.

A formalização econômica, uma imposição mercadológica e político-social advinda com globalização e a presença maior do Estado nestes locais, tem implicado na consideração de outras formas de legitimação da ordem social trabalhista, deixando de ser comunicativamente estabelecida para ser instrumentalmente implantada por intermédio da observação de leis trabalhistas o que 
CARNEIRO, R.N. \& GUEDES, J.A. Circuitos de fluxos sócioespaciais da...

tem permitido melhores condições de vida para uma parcela diminuta dos trabalhadores, particularmente mulheres, tendo em vista que os tipos de produtos fabricados em Jardim de Piranhas tem requerido o uso e mão de obra feminina (Figura 06-b).

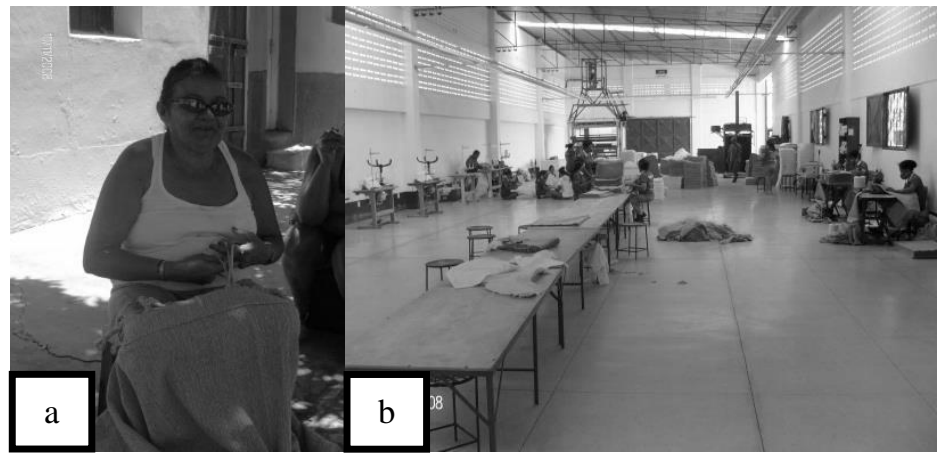

Figura 06: Feiteira ou artesã (a) e tecelagem formal (b). Foto: Os Autores.

A formalização, por sua vez, representando a presença maior do Estado no território de Jardim de Piranhas, significa também que a produção local passa a ser cada vez mais normatizada institucionalmente, e neste caso com especial destaque para os impactos ambientais gerados pelas empresas tanto do circuito superior secundário como pelas do circuito inferior.

\section{Impactos ambientais e circuitos de fluxos sócioespaciais em Jardim de Piranhas}

A grande maioria da população nos espaços de pesquisa se filia às atividades econômicas dos circuitos de fluxos sócioespaciais inferiores informais, sejam as unidades de produção familiar, doméstica, os serviços de distribuição prestados por comerciantes, portanto, ainda não tiveram a lógica de produção e reprodução sócioespacial de seu mundo vivido baseada na 
CARNEIRO, R.N. \& GUEDES, J.A. Circuitos de fluxos sócioespaciais da...

intersubjetividade da comunicação completamente substituídas pela lógica subjetivo-instrumental do mundo sistêmico.

Assim, quanto mais intensa a existência destes circuitos de fluxos sociais - incluindo os inferiores informais e formais e os superiores secundários e superiores não-hegemônicos maior a transformação da natureza humana existentes nas sociedades locais e da natureza material criadas por estas (CARNEIRO, 2008, p. 53).

Para Santos e Carneiro (2008, p.57):

A maior parte dos empresários de Jardim de Piranhas [...] recebeu dos pais o conhecimento tácito, isto é, adquirido ao longo da vida, sobre a tecelagem e tomaram para si a profissão como forma de sustentabilidade familiar. Tal fato mostra a reprodução desse mundo da vida.

Por outro lado, esta reprodução rebate nas relações sociedade-natureza através de impactos, pois historicamente esta atividade é poluente e se realiza sem preocupações de cunho protecionista, preservacionista ou conservacionista do ambiente local, seja natural, a exemplo da retirada de madeira para as fornalhas, seja social, pela exploração humana que realiza.

À medida que as normas de mercado e institucionais avançam celeremente neste mundo, as implicações sócioespaciais contraditórias do capital se instalam normatizando a vida produtiva e reprodutiva cotidiana. Por outro lado, como atesta Melo (2006, p. 79), após diagnostico realizado pelo SEBRAE/RN para implantação do Arranjo Produtivo Local de Tecelagem do Seridó

[...] foi constatada a preocupação com a gestão ambiental, onde as empresas demonstraram interesses em utilizar ferramentas que amenizassem o impacto causado ao meioambiente, já que a solução dos problemas tem elevado custo e só através da ação conjunta seria possível.

Vive-se hoje um momento de produção que tem abrangido toda a cadeia produtiva em vários setores econômicos e industriais. 
CARNEIRO, R.N. \& GUEDES, J.A. Circuitos de fluxos sócioespaciais da...

Devido a esse fato procura-se por meio de uma produção racional limpa minimizar impactos ambientais resultantes das linhas de produção. O desenvolvimento sustentável busca novas tecnologias que possam dar mais produção e gerar menos resíduos e, consequentemente, gerar mais produtividade.

Segundo Milan et al $(2010$, p. 5) a "[...] geração de resíduos é um fenômeno inevitável que ocorre nas indústrias diariamente em volumes e composições que variam conforme seu segmento de atuação e nível produtivo". Esses resíduos podem ser sobras do processo produtivo como tintas, fios, tecidos, etc., e podem gerar impactos ambientais caso não sejam bem armazenados ou tratados.

Durante a pesquisa foram identificados alguns impactos da atividade têxtil e que mostraram a ineficiência de política de uma melhor gestão ambiental dos resíduos. Alguns pontos de poluição foram identificados tanto na área urbana quanto na área rural.

A indústria têxtil tem dado sua contribuição quando se trata de resíduos sólidos como rolos de fios de tecelagem, plásticos e papelões (Figura 07). Através da aplicação das ferramentas da Produção Mais Limpa o SEBRAE/RN investiu em Jardim de Piranhas com o objetivo de diminuir a geração destes resíduos na própria fonte em que as mesmas são produzidas bem como reaproveita-los (MELO, 2006).

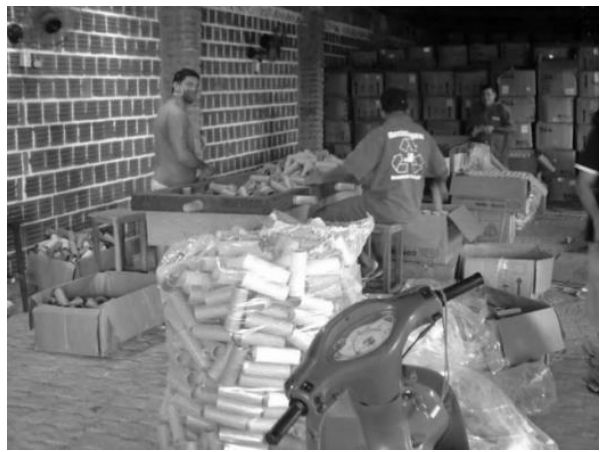

Figura 07: Reaproveitamento das "tabocas" ou cones de fios. Foto: Os Autores. 
CARNEIRO, R.N. \& GUEDES, J.A. Circuitos de fluxos sócioespaciais da...

Outra forma de resíduo são os corantes utilizados para colorir fios e tecidos em geral. Esses corantes são usados há muito tempo e classificados de acordo com o método como ele é fixado à fibra. Segundo Guaratini e Zanoni (1999)

[...] até a metade do século XIX, todos os corantes eram derivados de folhas, ramos, raízes, frutos ou flores de várias plantas e de substâncias extraídas de animal, embora venha sendo utilizado na Europa desde o século XIV.

A fase de coloração na lavagem corresponde a um dos maiores problemas que esse setor enfrenta, contribuindo com cerca de $15 \%$ de resíduos em nível mundial despejados no meio ambiente (GUARATINI \& ZANONI, 1999), mesmo assim novas estrategias estão sendo buscadas no sentido de minimizar esse impacto com a busca de melhor tratamento de efluente têxteis (KUNZ et al, 2000).

A Figura 08-a mostra o uso de produtos químicos durante o processo de tingimento das redes e de panos de prato. Após o tingimento, são descartados sem tratamento e despejados nas canalizações das ruas e, em seguida, atingem os esgotos a céu aberto, e por fim, seguem para o destino final, ou seja, são direcionados para o rio Piranhas-Açú, provocando impactos na qualidade da água do principal manancial da cidade (Figura 09-b).

Produtos químicos dessa natureza, podem ser considerados como agentes tóxicos, que para Finottiet al (2009) são produtos capazes $\mathrm{de}[. .$.$] produzir efeito tóxico, ou seja, alteração nas$ funções ou morte de um organismo (p.61), e dependendo da dose, podem provocar vários problemas de saúde, principalmente quando são encontrados diluídos na água captada do rio Piranhas-Açú. Mesmo que não tenha sido feitas análises dessa água pode-se perceber que ela interfere na qualidade da água, sendo perceptível a mudança de parâmetros como odor, sabor, $\mathrm{pH}$, cor e sólidos dissolvidos, mais perceptíveis visualmente (FINOTTI et al, 2009). 
CARNEIRO, R.N. \& GUEDES, J.A. Circuitos de fluxos sócioespaciais da...

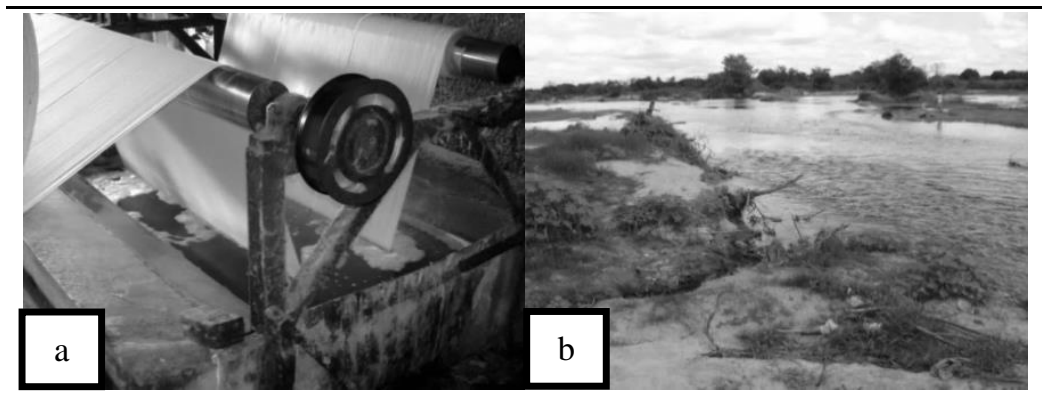

Figuras 08 e 09: Processo químico de alvejamento com cloro dos tecidos, com resíduos descartados de forma inadequada (a) e Canais com resíduos responsáveis por impactos no rio Piranhas-Açú (b). Foto: Os Autores.

Algumas empresas afirmam que possuem estação de tratamento de seus resíduos, uma vez que tencionam buscar reconhecimento por meio da ISO 14000 , o que facilitaria sua inserção no mercado muito competitivo e reconhecimento junto aos distribuidores e exportadores (Figura 10). Essas empresas buscam financiamentos junto a agencias de fomento no sentido de financiarem essas estações, já que elas correspondem a valor elevado inviável de ser construídas, segundo os empresários, caso não tenha financiamento adequado.

Ao longo das margens desse rio outros impactos ambientais foram identificados como a presença de pocilgas e esgotos residências escorrendo diretamente para as valetas das ruas, resíduos esses oriundos das pias e lavatórios das casas que não possuem fossas sépticas e, portanto, produzem impactos que poderiam ser minimizados caso houvesse tratamento de esgotos na cidade.

Vale salientar que existe um ponto de captação de água da Companhia de Águas e Esgotos do Estado do Rio Grande do Norte (CAERN) que abastece parte da cidade de Jardim de Piranhas. Nas imediações desse ponto de captação pode-se ver que existem além das pocilgas, a existência de lixos e de assoreamento, além do fato de estar na proximidade de uma rodovia estadual com tráfego 
CARNEIRO, R.N. \& GUEDES, J.A. Circuitos de fluxos sócioespaciais da... bastante elevado e que pode também contribuir com metais pesados e óleos e graxas (MOTA, 1995; FINOTTI et al, 2009).

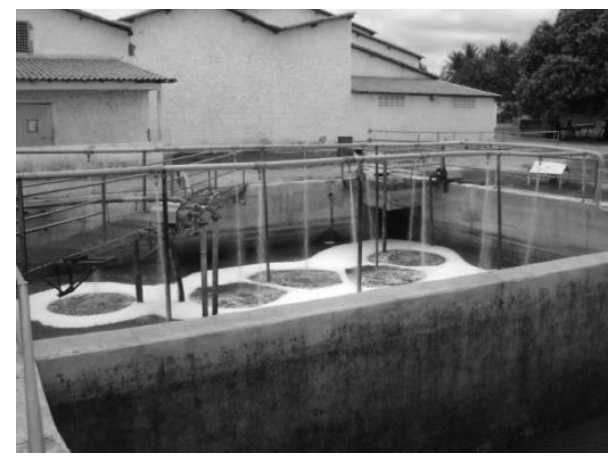

Figura 10: Estação de tratamento de efluentes de indústria têxtil local. Foto: Os Autores.

Durante as entrevistas foram reveladas alguns destinos para os resíduos sólidos, principalmente nas pequenas fábricas. Segundo os relatos parte desses resíduos são destinados ao lixão da cidade sem prévio tratamento e nem destino adequado. $\mathrm{Na}$ visita ao lixão pôde-se identificar que parte dos resíduos poderiam ter sido melhor reaproveitados, mas foram descartados de forma que contribuíam para o aumento maior dos impactos ambientais.

Segundo entrevista com pessoas que lidavam com o lixão, eles faziam reciclagem, mas aproveitavam todos os resíduos que ali aportavam, revelando, portanto, uma falta de estrutura no próprio lixão bem como falta de uma política de resíduos sólidos por parte da prefeitura.

\section{Conclusões}

A indústria têxtil de Jardim de Piranhas contribuiu historicamente de forma significativa para a geração de resíduos sólidos e líquidos poluentes, tanto do solo quanto dos mananciais, particularmente do rio Piranhas, que atravessa a cidade e é fonte de 
CARNEIRO, R.N. \& GUEDES, J.A. Circuitos de fluxos sócioespaciais da...

abastecimento d'água para consumo produtivo e consumptivo, cujos dejetos industriais são nele lançados ainda hoje, apesar da já antiga e tradicional fabricação têxtil local, historicamente realizada a base de utilização de produtos químicos poluentes e do descarte inapropriado de rejeitos materiais do processo produtivo, a exemplo de tabocas, pelos e fios.

Recentemente, porém, o Estado tem intervido de forma ativa localmente, combatendo os excessos de degradação ambiental e punido as empresas poluentes. Neste caso as mesmas têm sido orientadas a se adequarem a realidade ambiental, inclusive com a construção de estacoes de tratamento de dejetos.

$\mathrm{O}$ uso do fio de algodão tingido adquirido das fiações, por sua vez, apesar de mais caro que o fio de algodão cru, tem contribuído para a redução da utilização do cloro, utilizado para o branqueamento deste, bem como do uso de anilinas para tingimento dos mesmos. Estes produtos químicos ainda são vendidos localmente.

As unidades de produção fabris familiares e domiciliares pertencentes ao circuito de fluxos inferior informal bem como as microempresas pertencentes ao circuito de fluxos inferior formal parecem contribuir mais com a geração de resíduos sólidos, através das tabocas, e menos com os resíduos líquidos, já que tem utilizado menos ou negativamente cloro e tintas no processo produtivo, como se pode constatar nas pesquisas de campo, com as unidades de pesquisa entrevistadas.

Já as empresas de médio e grande porte, pertencentes ao circuito de fluxos superior secundário, a julgar pela existência e exigência governamental de construção de estações de tratamento de efluentes em algumas delas tem contribuído, sobretudo com os impactos ambientais dos recursos hídricos locais, a exemplo do rio Piranhas.

Os processos industriais e os fluxos socioeconômicos desta atividade tradicional do sertão nordestino têm contribuído para o fortalecimento do circuito espacial da produção na escala nacional (CEPN) de Jardim de Piranhas, cidade pequena situada na franja da 
CARNEIRO, R.N. \& GUEDES, J.A. Circuitos de fluxos sócioespaciais da...

economia global, contribuindo dessa forma, para surgimento e consolidação de novas esferas da economia globalizada.

Atrelada a esses processos, deve-se levar em consideração não apenas o crescimento e desenvolvimento econômico, mas também os problemas socioambientais que seguem atreladas à geração de diversos tipos de resíduos, oriundo da cadeia produtiva da indústria têxtil de fabricação de redes de dormir e pano de prato local.

Neste caso, o uso inadequado de matéria prima e, por conseguinte, seu descarte pode interferir não apenas no surgimento do circuito espacial da produção internacional (CEPI) da indústria têxtil de Jardim de Piranhas, alavancando sua produção ao nível da exportação para um mercado cada vez mais globalizado, a exemplo do município paraibano vizinho, São Bento, e concorrente direto, como pode causar rejeição no mercado nacional e regional.

As pequenas indústrias são aquelas que mais sofrem com essa problemática, pois nem sempre conseguem incentivos e parceria. $\mathrm{Na}$ área de estudo, as fábricas, especialmente as de médio porte, têm procurado dirimir esses problemas via construção de estações de tratamento, conseguindo verbas através de incentivo de agências de desenvolvimento.

\section{Referências bibliográficas}

CARNEIRO, R. N. A natureza do espaço numa perspectiva comunicativa ou pública. Boletim Goiano de Geografia. Goiânia, v.29, n.1, p.33-46, jan./jun., 2009.

- As interações sociedade e natureza nos espaços nordestinos de produção de redes de dormir e as configurações de seus meios geográficos. Rev. Geogr. Acadêmica, v.2, n.3, p. 5056, 2008.

. As semelhanças, diferenças e interações dos circuitos de fluxos sócioespaciais de redes de dormir do Nordeste brasileiro. Tese (Doutorado em Geografia) - Centro de Filosofia e Ciências Humanas, Universidade Federal de Pernambuco, Recife, 2011. 100 p. 
CARNEIRO, R.N. \& GUEDES, J.A. Circuitos de fluxos sócioespaciais da...

. Produção do espaço e circuitos de fluxos da indústria têxtil de São Bento-PB: do meio técnico ao meio técnicocientífico-informacional. 2006. 185 f. Dissertação (Mestrado em Geografia) - Centro de Filosofia e Ciências Humanas, Universidade Federal de Pernambuco, Recife, 2006.

FINOTTI, A. R.; FINKLER, R.; SILVA, M.D.; CEMIN, G. Monitoramento de recursos hídricos em áreas urbanas. Caxias do Sul: EDUCS, 2009.

GUARATINI, C. C. I.; ZANONI, M. V. B. Corantes têxteis. Química Nova, v.23, n.1, p.71-78, 2000.

HABERMAS, J. Teoría de la acción comunicativa: racionalidad de la acción y racionalización social. 4. ed. Madrid: Taurus, 2003. (v.1).

KUNZ, A.; PERALTA-ZAMORA, P.; MORAES, S. G.; DURÁN, N. Novas tendências no tratamento de efluentes têxteis. Química Nova, v.25, n.1, p.78-82, 2002.

MELO, F. V. P. de. Tecelagem do Seridó: na linha do desenvolvimento. In: SILVA, B. D. da (Org.) Histórias de sucesso do empreendedor potiguar. Natal: SEBRAE/RN, 2006. p. 73-86.

MILAN, G. S.; VITORIZZI, C.; REIS, Z. C. Um estudo sobre a redução de resíduos têxteis e de impactos ambientais em uma indústria de confecções do vestuário. Congresso Nacional de Excelência em Gestão, Niterói, RJ, ago. 2010. Anais... Niterói, p.1-24, 2010.

MOTA, S. Preservação e conservação de recursos hídricos.2 ed. Rio de Janeiro: ABES, 1995.

PESSOA, I. F. Arranjo produtivo de redes em Jaguaruana como apoio para o desenvolvimento local. 2003. $50 \mathrm{f}$. Monografia (Graduação em ciências econômicas). 
CARNEIRO, R.N. \& GUEDES, J.A. Circuitos de fluxos sócioespaciais da...

RAMOS, J. V. et. al. O pólo têxtil de Jardim de Piranhas-RN. In: - Colóquio Internacional: boas práticas territoriais no Brasil e na União Europeia. Brasília: Ministério da Integração Nacional, 2007.

SANTOS, J. E.; CARNEIRO, R. N; SÁ, A. J. Os mundos vividos de Jardim de Piranhas-RN e Tacaratu-PE e suas relações com os circuitos de fluxos sócioespaciais das indústrias têxteis de redes de dormir locais. Revista de Geografia. Recife: UFPE DCG/NAPA, v. 25, n. 1, jan./abr. 2008.

; CARNEIRO, R. N. Os mundos vividos de Jardim de Piranhas-RN e Tacaratu-PE e suas relações com os circuitos de fluxos sócioespaciais das indústrias têxteis de redes de dormir locais. Pau dos Ferros: PROPEG/DP/UERN, Relatório Final de projeto de pesquisa do Programa Institucional de Bolsas de Iniciação Científica - PIBIC/UERN. 2009.

SILVA, D. B. As relações de trabalho no espaço manufatureiro de rede-de-dormir - Boqueirão. 1997. 51 f. Monografia (Especialização em Regionalização e Análise Regional). - Centro de Educação, Universidade Estadual da Paraíba, Campina Grande, 1997.

Recebido em janeiro de 2012 Aceito em janeiro 2013 